Research Article

\title{
Prevalence of ocular disorders in Liberia: a retrospective study using the eyeSmart electronic medical record system
}

\author{
Anthony Vipin Das ${ }^{1}$, Priyanka Kammari ${ }^{1}$, Edward Bea Guizie ${ }^{2}$, Rajashekar Varada ${ }^{3}$, Gurcharan Singh ${ }^{2}$ \\ 1 Department of eyeSmart EMR \& AEye, L V Prasad Eye Institute, Hyderabad, Telangana, India, ${ }^{2}$ Department of Comprehensive Ophthalmology, \\ Liberia Eye Centre, Monrovia, Liberia, ${ }^{3}$ Gullapalli Pratibha Rao International Centre for Advancement of Rural Eye Care, L V Prasad Eye Institute, \\ Hyderabad, Telangana, India \\ Keywords: global health
}

https://doi.org/10.29392/joghr.3.e2019033

\section{Journal of Global Health Reports}

Vol. 3, 2019

\section{Background}

This study aims to describe the demographic distribution and ocular diagnosis of the patients presenting to the Liberia Eye Center, Monrovia, using the eyeSmart Electronic Medical Record system.

\section{Methods}

A retrospective study was conducted on patients presenting to Liberia Eye Center from July 2017 to July 2018. A total of 5258 patients were examined during this period. Data was collected from eyeSmart Electronic Medical Record system database. The variables in the collected data include age, gender, location, occupation, socioeconomic status, laterality of eye affected, and ocular diagnosis. All the counties were included in the study. A total of 8234 instances of ocular diagnosis were made in 5258 patients.

\section{Results}

Of the total 5258 patients, the majority of them presented from the county of Lofa (18.77\%) and the least number of patients from Gbarpolu (1.62\%). Out of the total children examined (16 years and under), females outnumbered males (8.25\% vs. $4.87 \%)$. Among the adults, almost equal number of males (50.1\%) and females (49.9\%) presented to the clinic. The most common diagnosis was uncorrected refractive errors (34.89\%) followed by the cornea and anterior segment disorders, cataract and glaucoma in that order. But in children aged 16 years and under, cornea and anterior segment related disorders (6.01\%) were the most common diagnosis and the least common diagnosis was amblyopia (0.34\%). Majority of the patients were unemployed (60.54\%) and the most common profession in the remaining cohort was a student (8.96\%).

\section{Conclusions}

Refractive error was found to be the most common ocular diagnosis and the second most common presentation was cornea and anterior segment disorders in Liberian population. In children aged 16 years and under, cornea and anterior segment related disorders were the most common ocular diagnosis. The description of various ocular diseases and their clinical presentation for the first time in a Liberian population provides the opportunity for further research. The digitization of eye care using electronic medical record systems is a progressive step forward to help formulate strategies for health policy to combat avoidable blindness across Liberia.

The Republic of Liberia is a West African country bordered by Guinea, Ivory Coast, Sierra Leone, and the Atlantic Ocean. As of the 2017 national census, Liberia was home to $4,694,608$ people. $^{1}$ The country is divided into 15 counties which are subdivided into several districts. Based on the review of literature, the published data related to ophthalmology from Liberia is limited. Apart from a few papers on the description of Onchocerciasis in Liberia ${ }^{2}$ to an overview of Ophthalmology in developing countries, ${ }^{3}$ there is no comprehensive study till date that describes the burden of ocular diseases in the Liberian population.

In 1993, Frucht-Pery et al described 43 eyes of 30 patients with ocular leprosy who underwent cataract extraction; 33 eyes had extracapsular cataract extraction (ECCE) and 10 eyes had intracapsular cataract extraction (ICCE). ${ }^{4}$ There have been sporadic case reports described of West African crystalline maculopathy ${ }^{5}$ and Mycobacterium tuberculosis presenting as the chronic red eye. ${ }^{6}$ As per the 
Rapid Assessment of Avoidable Blindness (RAAB) 2012, conducted by the Ministry of Health and social welfare, Republic of Liberia in 2012, the prevalence of blindness was associated with increasing age ranging from $0.7 \%$ in those aged $50-54$ years to $11.7 \%$ in those aged 80 years and above. Cataract accounted for $60.4 \%$ of blindness. Posterior segment pathologies accounted for $27.8 \%$ of blindness in people in the study. Over half (16\%) of the posterior segment blindness was due to glaucoma. Surgical complications accounted for $4.2 \%$ of blindness followed by non-trachomatous corneal opacities (3.5\%), and uncorrected aphakia (2.8\%). Refractive error was not a cause of blindness. ${ }^{7}$

A study in 2017 was conducted by Shantha et al to describe the ocular findings, visual impairment, and association of structural complications of uveitis with visual impairment in a cohort of survivors of Ebola virus disease (EVD) in Monrovia, Liberia. ${ }^{7}$ A cohort of EVD survivors who underwent baseline ophthalmic evaluation at ELWA Hospital was retrospectively reviewed for demographic information, length of Ebola treatment unit (ETU) stay, visual acuity (VA), and ophthalmic examination findings. For patients with uveitis, disease activity (active vs. inactive) and grade of inflammation were recorded according to Standardization of Uveitis Nomenclature criteria. ${ }^{8}$

As there is a lacuna in the literature of the eye disease burden in Liberia and the spectrum of conditions presenting for treatment, this study generates new insights in the given geographic region. The establishment of digital systems to capture clinical information related to Ophthalmology in Liberia also has not been described so far in the literature.

\section{METHODS}

A retrospective study was performed on records of patients presenting to the Liberia Eye Centre, John F. Kennedy Memorial Medical center, Monrovia, Liberia from July 2017 to July 2018.

The medical records of all patients who presented to the Liberia Eye Centre between July 2017 and July 2018 were reviewed retrospectively using the eyeSmart EMR (electronic medical records) database. A total of 5258 patients were examined during this period with the age range of 0 to 100 years. The paediatric age group was categorized under age less than or equal to 16 years and adults were considered as above 16 years of age. The variables in the collected data include age, gender, location, occupation, socioeconomic status, laterality of eye affected, and ocular diagnosis. The patients who did not have any of these variables for analysis were excluded from the study. All the 15 counties of Liberia were included in the study. The location as informed by the patient was captured at the time of registration into the eyeSmart EMR system at the Liberia eye center. The occupation of the patients who presented to the Liberia eye center were of 93 different types and the top ten occupations were used for analysis. Each eye of all the 5258 patients was diagnosed separately. A total of 8234 instances of ocular diagnosis were made in 5258 patients. These were categorized into amblyopia, cataract, cornea and anterior segment disorders, glaucoma, neuro-ophthalmology, ocular trauma, refractive error, retina, uvea and strabismus.
'eyeSmart EMR' is an indigenously built electronic medical record system at the LV Prasad Eye Institute, Hyderabad, India. The system allows the documentation of clinical information of patients in a structured manner that allows analysis for research purposes. The information from the database is analyzed to provide a real time overview. The live dashboard of the patients presenting to the Liberia eye center since July 2017 can be accessed at the following link - https://www.lvpei.org/aeye/lec.html.

\section{STATISTICAL ANALYSIS}

The data was retrieved from the Electronic Medical Record (eyeSmart EMR) database and segregated into an Excel spreadsheet. Microsoft Office Excel 2013 version (Microsoft Inc., Seattle, WA, USA) was used to perform the statistical analysis. Normality of the continuous data was evaluated using Shapiro-Wilk test. The distributions of variables like age were plotted separately. The detailed description of each independent variable with other dependent variables was described in table formats using pivot tables. In each table the unavailable data was mentioned as "not available". Methodology of this study followed the STROBE checklist where relevant. ${ }^{9}$

\section{ETHICS APPROVAL}

The study was approved by the University of Liberia National Institutional Review Board and L V Prasad Eye Institute's Institutional Review Board and adhered to tenets of Declaration of Helsinki.

\section{RESULTS}

A total of 5258 patients with age ranging from 0 to 100 years presented to the Liberia eye center during the study period. Of them, 50.1\% $(\mathrm{N}=2634)$ were males and $49.9 \%(\mathrm{~N}=2624)$ were females.

\section{AGE}

The mean age of the patients was $43.56 \pm 21.24$ (standard deviation, SD) years while the median age was 45 years (range: $<1$ to 100 years). Of the 5,258 patients 690 (13.1\%) were children aged less than or equal to 16 years and 4568 (86.8\%) were adults greater than 16 years. The majority of the patients age ranged from 30 to 70 years $(\mathrm{N}=3873$; $73.7 \%)$ and the remaining ranged from 0 to $29(\mathrm{~N}=891$; $16.9 \%)$ and 71 to 100 years $(\mathrm{N}=494 ; 9.4 \%)$ (Figure 1$)$. In the pediatric age group, $256(4.87 \%)$ were males and 434 (8.25\%) were females. In adults, 2378 (45.23\%) were males and 2190 (41.65\%) were females. The age decade wise distribution of patients is presented in Figure 1.

The decade of 41 to 50 years age had the highest distribution with 906 (17.23\%) patients and the decade of 91 to 100 years $(\mathrm{N}=12 ; 0.23 \%)$ has the lowest distribution. The distribution of pediatric ( $<16$ years), adult ( $>16-60$ years) and elderly (>60 years) was 690 (13.12\%), 3326 (63.26\%) and 1242 (23.62\%) respectively. 
Table 1. Distribution age and gender of all the patients presenting to the Liberia eye center

\begin{tabular}{cccc}
\hline Age (Years) & Male (N, \%) & Female (N, \%) & Total (N, \%) \\
\hline $0-10$ & $162(3.08)$ & $290(5.52)$ & $452(8.60)$ \\
$11-20$ & $186(3.54)$ & $253(4.81)$ & $439(8.35)$ \\
$21-30$ & $265(5.04)$ & $289(5.50)$ & $554(10.54)$ \\
$31-40$ & $388(7.38)$ & $376(7.15)$ & $764(14.53)$ \\
$41-50$ & $474(9.01)$ & $432(8.22)$ & $906(17.23)$ \\
$51-60$ & $491(9.34)$ & $410(7.80)$ & $901(17.14)$ \\
$61-70$ & $423(8.04)$ & $325(6.18)$ & $748(14.23)$ \\
$71-80$ & $177(3.37)$ & $185(3.52)$ & $362(6.88)$ \\
$81-90$ & $62(1.18)$ & $58(1.10)$ & $120(2.28)$ \\
$91-100$ & $6(0.11)$ & $6(0.11)$ & $12(0.23)$ \\
Grand Total & $2634(50.10)$ & $2624(49.90)$ & $5258(100)$ \\
\hline
\end{tabular}

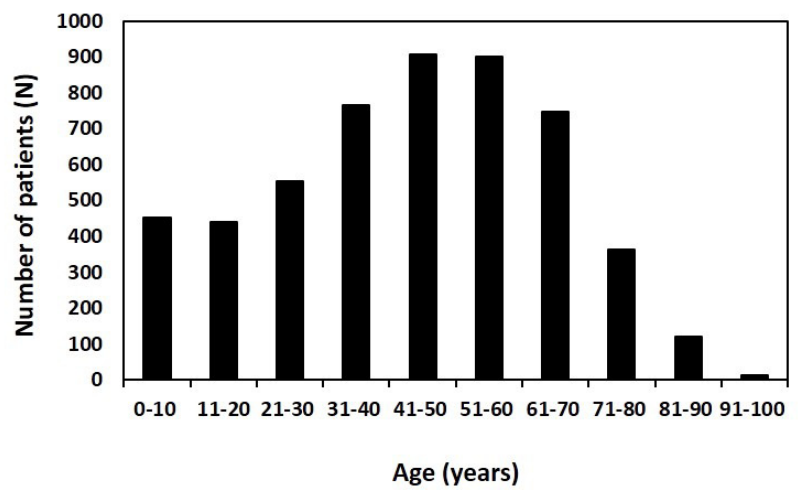

Figure 1. Distribution of age of all the patients presented to Liberia eye center.

\section{GENDER}

Of these 5,258 patients, 2,634 (50.1\%) were males and 2,624 (49.9\%) were females, indicating an equitable access to eyecare services among both genders. The highest proportion of males was in the $5^{\text {th }}$ decade with 491 (9.34\%) patients and in females was in the $4^{\text {th }}$ decade with 432 (8.22\%) patients. With the exception of the pediatric age group, the proportion of male patients was higher than females at presentation as described in Table 1.

\section{DIAGNOSIS}

Of 5258 patients, the ocular diagnosis was made for each eye and a total of 8234 were made during the study period. The majority of the ocular diagnosis was made in both eyes $(\mathrm{N}=5229 ; 63.50 \%)$. The distribution of each diagnosis category is described in Table 2 . The most common diagnosis made was refractive errors ( $\mathrm{N}=2873 ; 34.89 \%)$. The second common diagnosis category was cornea and anterior segment diseases $(\mathrm{N}=2548$; 30.94\%) followed by cataract ( $\mathrm{N}=1162 ; 14.11 \%$ ) (Table 2).

The gender distribution based on diagnosis category was almost equal in proportion with 4188 (50.86\%) male patients and 4046 (49.14\%) female patients. The majority of the ocular diagnosis was made in adults whose age was greater than 16 years $(\mathrm{N}=7397 ; 89.93 \%)$ and the rest in the pediatric age group $(\mathrm{N}=837 ; 10.17 \%)$. Overall, the most common diagnosis in adults aged $>16$ years was refractive errors with $\mathrm{N}=2783$ ( $33.80 \%)$. In children aged $\leqslant 16$ years the common diagnosis was related to the cornea and anterior segment $(\mathrm{N}=90 ; 1.09 \%)$. Both the diagnosis of refractive errors and cornea and anterior segment disorders had an equal distribution in male and female patients (Table 3 and Table 4).

\section{OCCUPATION}

The occupations of the 5,258 patients who presented to the Liberia eye center were 93 different types. Of them, the top ten occupations are listed in Table 5. Majority of the patients were unemployed ( $\mathrm{N}=3183 ; 60.54 \%)$. The employment status was not applicable in $\mathrm{N}=297$ (5.65\%) patients. Of the ones that were documented in the system, the most common profession was a student $(\mathrm{N}=471 ; 8.96 \%)$. The second common occupation was business ( $\mathrm{N}=266 ; 5.06 \%)$ followed by an accountant ( $\mathrm{N}=109 ; 2.29 \%)$.

\section{SOCIO-ECONOMIC STATUS}

The socio-economic status of the 5,258 patients as per the status recorded when the patient presented for eye examination were of two types-paying ( $\mathrm{N}=3769 ; 71.68 \%)$ and nonpaying ( $\mathrm{N}=1489 ; 28.32 \%)$. As per socio-economic status, the majority of the patients were males $(\mathrm{N}=1955$; $37.18 \%)$ in the paying category, and females $(\mathrm{N}=810$; $15.41 \%)$ in the nonpaying category Table 6.

\section{COUNTY DISTRIBUTION}

The 5258 patients who presented to Liberia eye center were from 15 counties across the country. The count of patients who presented from outside the country of Liberia were $\mathrm{N}=15$ (0.29\%). Majority of the patients presented to Liberia eye center were from the county of Lofa ( $\mathrm{N}=987 ; 18.77 \%)$. The second common county where patients presented was Montserrado ( $\mathrm{N}=843 ; 16.03 \%)$ followed by the county of Bong $(\mathrm{N}=595 ; 11.32 \%)$. The gender distribution in all these locations was nearly equal in proportion. Males were 2634 (50.10\%) and females were 2624 (49.9\%). The distribution 
Table 2. Distribution of diagnosis category of patients presenting to the Liberia eye center

\begin{tabular}{|c|c|c|}
\hline Diagnosis category & $\mathrm{N}$ value & $\mathrm{N} \%$ \\
\hline Refractive error & 2873 & 34.89 \\
\hline Cornea \& anterior segment & 2548 & 30.94 \\
\hline Cataract & 1162 & 14.11 \\
\hline Glaucoma & 586 & 7.12 \\
\hline Retina & 421 & 5.11 \\
\hline Ocular trauma & 201 & 0.34 \\
\hline Oculoplasty & 200 & 2.43 \\
\hline Neuro-ophthalmology & 120 & 1.46 \\
\hline Uvea & 51 & 0.62 \\
\hline Strabismus & 44 & 0.53 \\
\hline Amblyopia & 28 & 0.34 \\
\hline Grand Total & 8234 & 100.00 \\
\hline
\end{tabular}

Table 3. Distribution diagnosis category based on gender

\begin{tabular}{lccc}
\hline Diagnosis category & Male $-\mathbf{N}(\%)$ & Female- N (\%) & Grand Total \\
\hline Refractive error & $1406(17.08)$ & $1467(17.82)$ & $2873(34.89)$ \\
Cornea \& anterior segment & $1250(15.18)$ & $1298(15.76)$ & $2548(30.94)$ \\
Cataract & $607(7.37)$ & $555(6.74)$ & $1162(14.11)$ \\
Glaucoma & $370(4.49)$ & $216(2.62)$ & $586(7.12)$ \\
Retina & $233(2.83)$ & $188(2.28)$ & $421(5.11)$ \\
Ocular trauma & $111(1.35)$ & $90(1.09)$ & $201(2.44)$ \\
Oculoplasty & $102(1.24)$ & $98(1.19)$ & $200(2.43)$ \\
Neuro-ophthalmology & $54(0.66)$ & $66(0.80)$ & $120(1.46)$ \\
Uvea & $28(0.34)$ & $23(0.28)$ & $51(0.62)$ \\
Strabismus & $17(0.21)$ & $27(0.33)$ & $44(0.53)$ \\
Amblyopia & $10(0.12)$ & $18(0.22)$ & $28(0.34)$ \\
Grand Total & $4188(50.86)$ & $4046(49.14)$ & $8234(100)$ \\
\hline
\end{tabular}

Table 4. Distribution diagnosis category based on age category

\begin{tabular}{lccc}
\hline Diagnosis category & Age $\leq 16$ years & Age $>16$ years & Grand Total \\
\hline Refractive error & $90(1.09)$ & $2783(33.80)$ & $2873(34.89)$ \\
Cornea \& anterior segment & $495(6.01)$ & $2053(24.93)$ & $2548(30.94)$ \\
Cataract & $54(0.66)$ & $1108(13.46)$ & $1162(14.11)$ \\
Glaucoma & $17(0.21)$ & $569(6.91)$ & $586(7.12)$ \\
Retina & $21(0.26)$ & $400(4.86)$ & $421(5.11)$ \\
Ocular trauma & $49(0.60)$ & $152(1.85)$ & $201(2.44)$ \\
Oculoplasty & $56(0.68)$ & $144(1.75)$ & $200(2.43)$ \\
Neuro-ophthalmology & $16(0.19)$ & $104(1.26)$ & $120(1.46)$ \\
Uvea & $3(0.04)$ & $48(0.58)$ & $51(0.62)$ \\
Strabismus & $20(0.24)$ & $24(0.29)$ & $44(0.53)$ \\
Amblyopia & $16(0.19)$ & $12(0.15)$ & $28(0.34)$ \\
Grand total & $837(10.17)$ & $7397(89.93)$ & $8234(100)$ \\
\hline
\end{tabular}

of males and females who presented to Liberia eye Centre from the county of Lofa were 481 (9.15\%) and 506 (9.62\%) respectively (Table 7).
Majority of the ocular disease was noticed in Lofa county $(\mathrm{N}=1587 ; 19.32 \%)$. The most common ocular diseases in this county were refractive errors (586; 7.13\%). The less common ocular disease was amblyopia $(\mathrm{N}=3 ; 0.03 \%)$. The least pro- 
Table 5. Distribution of top ten occupations of the Liberian population presenting to the Liberia eye center

\begin{tabular}{lcc}
\hline Occupation & N value & N\% \\
\hline Unemployment & 3183 & 60.54 \\
Student & 471 & 8.96 \\
Not applicable & 297 & 5.65 \\
Business & 266 & 5.06 \\
Accountant & 109 & 2.07 \\
Administrator & 109 & 2.07 \\
\hline Teacher & 109 & 2.07 \\
Nurse & 95 & 1.81 \\
\hline Driver & 78 & 1.48 \\
\hline Housewife & 56 & 1.07 \\
\hline
\end{tabular}

Table 6. Distribution of socio-economic status based on gender

\begin{tabular}{lccc}
\hline Parameter & Male (N, \%) & Female (N, \%) & Total (N, \%) \\
\hline Paying & $1955(37.18)$ & $1814(34.50)$ & $3769(71.68)$ \\
Non Paying & $679(12.91)$ & $810(15.41)$ & $1489(28.32)$ \\
Grand Total & $2634(50.10)$ & $2624(49.90)$ & $5258(100)$ \\
\hline
\end{tabular}

Table 7. Distribution of gender based on location

\begin{tabular}{lccc}
\hline County & Male (N, \%) & Female (N, \%) & Total (N, \%) \\
\hline Bomi & $76(1.45)$ & $96(1.83)$ & $172(3.27)$ \\
\hline Bong & $290(5.52)$ & $305(5.80)$ & $595(11.32)$ \\
\hline Gbarpolu & $48(0.91)$ & $37(0.70)$ & $85(1.62)$ \\
Grand Bassa & $232(4.41)$ & $252(4.79)$ & $484(9.21)$ \\
\hline Grand Cape Mount & $138(2.62)$ & $139(2.64)$ & $277(5.27)$ \\
Grand Gedeh & $59(1.12)$ & $60(1.14)$ & $119(2.26)$ \\
Grand Kru & $111(2.11)$ & $135(2.57)$ & $246(4.68)$ \\
Lofa & $481(9.15)$ & $506(9.62)$ & $987(18.77)$ \\
Margibi & $105(2.00)$ & $59(1.12)$ & $164(3.12)$ \\
\hline Maryland & $172(3.27)$ & $228(4.34)$ & $400(7.61)$ \\
Montserrado & $459(8.73)$ & $384(7.30)$ & $843(16.03)$ \\
Nimba & $195(3.71)$ & $177(3.37)$ & $372(7.07)$ \\
\hline River Gee & $55(1.05)$ & $47(0.89)$ & $102(1.94)$ \\
\hline Rivercess & $57(1.08)$ & $52(0.99)$ & $109(2.07)$ \\
\hline Sinoe & $147(2.80)$ & $141(2.68)$ & $288(5.48)$ \\
\hline Not Applicable & $9(0.17)$ & $6(0.11)$ & $15(0.29)$ \\
\hline Grand Total & $2634(50.10)$ & $2624(49.90)$ & $5258(100)$ \\
\hline
\end{tabular}

portion of patients who presented to the Liberia eye center hailed from Gbarpolu ( $\mathrm{N}=131 ; 1.59 \%)$. The common ocular diseases in this county were related to the cornea and anterior segment disorders $(\mathrm{N}=36 ; 0.44 \%)$. The detailed distribution of each disease category in a particular location is described in Table 8 .

\section{DISCUSSION}

To the best of our knowledge, the existing literature related to Ophthalmology from Liberia is limited. There is no com- prehensive study till date that describes the burden of eye diseases in the Liberian population. Our study tried to bridge the existing lacunae and enables to generate new insights in the given geographic location. The distribution of factors like age, gender demographics, socio-economic status, and ocular diagnosis was described in detail in this study. Majority of patients presented from the county of Lofa (18.77\%) followed by Montserrado and Bong. Gbarpolu (1.62\%) had the least number of patients presenting to the eye center. Out of the total children examined (16 years and under), females outnumbered males (8.25\% vs. $4.87 \%$ ). 
Table 8. Distribution of diagnosis categories based on location

\begin{tabular}{|c|c|c|c|c|c|c|c|c|c|c|c|c|}
\hline Location & Amblyopia & Cataract & $\begin{array}{l}\text { Cornea \& } \\
\text { Anterior } \\
\text { Segment }\end{array}$ & Glaucoma & $\begin{array}{c}\text { Neuro- } \\
\text { Ophthalmology }\end{array}$ & $\begin{array}{l}\text { Ocular } \\
\text { Trauma }\end{array}$ & $\begin{array}{l}\text { Oculo- } \\
\text { plasty }\end{array}$ & $\begin{array}{l}\text { Refractive } \\
\text { Error }\end{array}$ & Retina & Strabismus & Uvea & $\begin{array}{l}\text { Grand } \\
\text { Total }\end{array}$ \\
\hline Bomi & $1(0.01)$ & $\begin{array}{c}46 \\
(0.55)\end{array}$ & 89 (1.08) & $22(0.27)$ & $4(0.05)$ & $5(0.06)$ & $\begin{array}{c}6 \\
(0.07)\end{array}$ & $96(1.17)$ & $\begin{array}{c}8 \\
(0.10)\end{array}$ & $2(0.02)$ & $\begin{array}{c}2 \\
(0.02)\end{array}$ & $\begin{array}{c}281 \\
(3.41)\end{array}$ \\
\hline Bong & $4(0.04)$ & $\begin{array}{c}133 \\
(1.61)\end{array}$ & $284(3.46)$ & $72(0.88)$ & $13(0.16)$ & $\begin{array}{c}28 \\
(0.34)\end{array}$ & $\begin{array}{c}24 \\
(0.29)\end{array}$ & $330(4.02)$ & $\begin{array}{c}39 \\
(0.47)\end{array}$ & $3(0.04)$ & $\begin{array}{c}7 \\
(0.09)\end{array}$ & $\begin{array}{c}937 \\
(11.38)\end{array}$ \\
\hline Gbarpolu & $1(0.01)$ & $\begin{array}{c}33 \\
(0.40)\end{array}$ & $36(0.44)$ & $12(0.15)$ & $0(0)$ & $3(0.04)$ & $\begin{array}{c}2 \\
(0.02)\end{array}$ & $32(0.39)$ & $\begin{array}{c}12 \\
(0.15)\end{array}$ & $0(0)$ & $0(0)$ & $\begin{array}{c}131 \\
(1.59)\end{array}$ \\
\hline Grand Bassa & $1(0.01)$ & $\begin{array}{c}115 \\
(1.39)\end{array}$ & $246(2.99)$ & $46(0.56)$ & $10(0.12)$ & $\begin{array}{c}13 \\
(0.16)\end{array}$ & $\begin{array}{c}19 \\
(0.23)\end{array}$ & $234(2.85)$ & $\begin{array}{c}34 \\
(0.41)\end{array}$ & $6(0.07)$ & $\begin{array}{c}6 \\
(0.07)\end{array}$ & $\begin{array}{c}730 \\
(8.88)\end{array}$ \\
\hline $\begin{array}{l}\text { Grand Cape } \\
\text { Mount }\end{array}$ & $1(0.01)$ & $\begin{array}{c}59 \\
(0.71)\end{array}$ & $135(1.64)$ & $35(0.43)$ & $5(0.06)$ & $\begin{array}{c}10 \\
(0.12)\end{array}$ & $\begin{array}{c}13 \\
(0.16)\end{array}$ & $147(1.79)$ & $\begin{array}{c}27 \\
(0.33)\end{array}$ & $2(0.02)$ & $\begin{array}{c}2 \\
(0.02)\end{array}$ & $\begin{array}{c}436 \\
(5.30)\end{array}$ \\
\hline $\begin{array}{l}\text { Grand } \\
\text { Gedeh }\end{array}$ & $1(0.01)$ & $\begin{array}{c}30 \\
(0.36)\end{array}$ & $60(0.73)$ & $15(0.18)$ & $3(0.04)$ & $5(0.06)$ & $\begin{array}{c}6 \\
(0.07)\end{array}$ & $59(0.72)$ & $\begin{array}{c}9 \\
(0.11)\end{array}$ & 1 (0.01) & $\begin{array}{c}2 \\
(0.02)\end{array}$ & $\begin{array}{c}191 \\
(2.32)\end{array}$ \\
\hline Grand Kru & $2(0.02)$ & $\begin{array}{c}56 \\
(0.68)\end{array}$ & $116(1.41)$ & $27(0.33)$ & $9(0.11)$ & $\begin{array}{c}12 \\
(0.15)\end{array}$ & $\begin{array}{c}9 \\
(0.11)\end{array}$ & $127(1.55)$ & $\begin{array}{c}19 \\
(0.23)\end{array}$ & $1(0.01)$ & $0(0)$ & $\begin{array}{c}378 \\
(4.59)\end{array}$ \\
\hline Lofa & $3(0.03)$ & $\begin{array}{c}255 \\
(3.10)\end{array}$ & $449(5.47)$ & $122(1.49)$ & $21(0.26)$ & $\begin{array}{c}29 \\
(0.35)\end{array}$ & $\begin{array}{c}34 \\
(0.41)\end{array}$ & $586(7.13)$ & $\begin{array}{c}70 \\
(0.85)\end{array}$ & $9(0.11)$ & $\begin{array}{c}9 \\
(0.11)\end{array}$ & $\begin{array}{c}1587 \\
(19.27)\end{array}$ \\
\hline Margibi & $1(0.01)$ & $\begin{array}{c}48 \\
(0.58)\end{array}$ & $76(0.93)$ & $22(0.27)$ & $3(0.04)$ & $4(0.05)$ & $\begin{array}{c}5 \\
(0.06)\end{array}$ & $68(0.83)$ & $\begin{array}{c}19 \\
(0.23)\end{array}$ & $0(0)$ & $\begin{array}{c}1 \\
(0.01)\end{array}$ & $\begin{array}{l}247 \\
(3.0)\end{array}$ \\
\hline Maryland & $0(0)$ & $\begin{array}{c}69 \\
(0.83)\end{array}$ & $216(2.63)$ & $54(0.66)$ & $8(0.10)$ & $9(0.11)$ & $\begin{array}{c}12 \\
(0.15)\end{array}$ & $232(2.82)$ & $\begin{array}{c}33 \\
(0.40)\end{array}$ & $4(0.05)$ & $\begin{array}{c}8 \\
(0.10)\end{array}$ & $\begin{array}{c}645 \\
(7.83)\end{array}$ \\
\hline Montserrado & $8(0.09)$ & $\begin{array}{c}129 \\
(1.57)\end{array}$ & $410(4.99)$ & $67(00.82)$ & $14(0.17)$ & $\begin{array}{c}50 \\
(0.61)\end{array}$ & $\begin{array}{c}29 \\
(0.35)\end{array}$ & 492 (5.99) & $\begin{array}{c}74 \\
(0.90)\end{array}$ & $5(0.06)$ & $\begin{array}{c}5 \\
(0.06)\end{array}$ & $\begin{array}{c}1283 \\
(15.58)\end{array}$ \\
\hline Nimba & $2(0.02)$ & $\begin{array}{c}62 \\
(0.75)\end{array}$ & $190(2.31)$ & $26(0.32)$ & $14(0.17)$ & $\begin{array}{c}21 \\
(0.26)\end{array}$ & $\begin{array}{c}16 \\
(0.19)\end{array}$ & $194(2.36)$ & $\begin{array}{c}33 \\
(0.40)\end{array}$ & $8(0.10)$ & $\begin{array}{c}4 \\
(0.05)\end{array}$ & $\begin{array}{c}570 \\
(6.92)\end{array}$ \\
\hline River Gee & $0(0)$ & $\begin{array}{c}20 \\
(0.24)\end{array}$ & $47(0.57)$ & $13(0.16)$ & $3(0.04)$ & $2(0.02)$ & $\begin{array}{c}7 \\
(0.09)\end{array}$ & $46(0.56)$ & $\begin{array}{c}10 \\
(0.12)\end{array}$ & $1(0.01)$ & $\begin{array}{c}3 \\
(0.04)\end{array}$ & $\begin{array}{c}152 \\
(1.85)\end{array}$ \\
\hline Rivercess & $1(0.01)$ & $\begin{array}{c}33 \\
(0.40)\end{array}$ & $45(0.55)$ & $20(0.24)$ & $4(0.05)$ & $2(0.02)$ & $\begin{array}{c}4 \\
(0.05)\end{array}$ & $67(0.82)$ & $\begin{array}{c}13 \\
(0.16)\end{array}$ & $0(0)$ & $\begin{array}{c}1 \\
(0.01)\end{array}$ & $\begin{array}{c}190 \\
(2.31)\end{array}$ \\
\hline Sinoe & $2(0.02)$ & $\begin{array}{c}73 \\
(0.88)\end{array}$ & $139(1.69)$ & $32(0.39)$ & $8(0.10)$ & $8(0.10)$ & $\begin{array}{c}13 \\
(0.16)\end{array}$ & $158(1.92)$ & $\begin{array}{c}19 \\
(0.23)\end{array}$ & $2(0.02)$ & $\begin{array}{c}1 \\
(0.01)\end{array}$ & $\begin{array}{c}455 \\
(5.53)\end{array}$ \\
\hline $\begin{array}{l}\text { Not } \\
\text { applicable }\end{array}$ & $0(0)$ & $1(0.1)$ & $10(0.12)$ & $1(0.01)$ & $1(0.01)$ & $0(0)$ & $\begin{array}{c}1 \\
(0.01)\end{array}$ & $5(0.06)$ & $\begin{array}{c}2 \\
(0.02)\end{array}$ & $0(0)$ & $\begin{array}{c}1 \\
(0.01)\end{array}$ & $\begin{array}{c}21 \\
(0.26)\end{array}$ \\
\hline Grand Total & $28(0.34)$ & 1162 & 2548 & 586 (7.12) & $120(1.46)$ & 201 & 200 & 2873 & 421 & $44(0.53)$ & 51 & 8234 \\
\hline
\end{tabular}




\begin{tabular}{|c|c|c|c|c|c|c|c|c|c|c|c|c|}
\hline Location & Amblyopia & Cataract & $\begin{array}{l}\text { Cornea \& } \\
\text { Anterior } \\
\text { Segment }\end{array}$ & Glaucoma & $\begin{array}{c}\text { Neuro- } \\
\text { Ophthalmology }\end{array}$ & $\begin{array}{l}\text { Ocular } \\
\text { Trauma }\end{array}$ & $\begin{array}{l}\text { Oculo- } \\
\text { plasty }\end{array}$ & $\begin{array}{l}\text { Refractive } \\
\text { Error }\end{array}$ & Retina & Strabismus & Uvea & $\begin{array}{l}\text { Grand } \\
\text { Total }\end{array}$ \\
\hline & & $(14.11)$ & (30.94) & & & $(2.44)$ & $(2.43)$ & (34.89) & $(5.11)$ & & $(0.62)$ & (100) \\
\hline
\end{tabular}


Among the adults, almost equal number of males (50.1\%) and females (49.9\%) presented to the clinic implying equal awareness among both genders to access eye care services. Overall, the most common diagnosis was uncorrected refractive errors (34.89\%) followed by cornea and anterior segment disorders, cataract and glaucoma in that order. But in children aged 16 years and under, cornea and anterior segment related disorders (6.01\%) accounted for the most common diagnosis. The least common diagnosis was amblyopia (0.34\%). Majority of the patients were unemployed (60.54\%) followed by the student (most common), business and accountant as a profession in that order. Over onefourth patients $(28.32 \%)$ could not afford their eye examination and were in the non-paying category. Only $13.1 \%$ of the patients belonged to the pediatric age group and there is a need to increase awareness among the population to enable screening among this group.

As per the Rapid Assessment of Avoidable Blindness $(\mathrm{RAAB})^{6}$ 2012, Liberia report, corneal opacities accounted for $3.2 \%$ of blindness whereas in the present study cornea and anterior segment disorders (30.94\%) were the second most common presentation. Refractive error was not a cause of blindness as per RAAB report as opposed to the present study where we found it to be the most common diagnosis (34.89\%). This difference could be due to exclusion of population under 50years age from the study in RAAB. There is a more comprehensive view of the burden of disease distribution as the current study included patients of all age groups.

The biggest strength of the study is the inclusion of a large sample for describing the burden of ocular diseases in Liberian population ( $\mathrm{N}=5258$ patients). The demographic distribution of patients is also spread across all the 15 counties of the country. Digitization brings with it the added benefits of structured entry of clinical information and the ability to analyze the data for insights. Establishment of electronic medical record systems enables us to have the information in real time. ${ }^{10}$ eyeSmart EMR allows us to capture and visualize the ocular disease burden of the patients presenting across Liberia. A real-time dash-board of the ocular diseases of the patients presenting to the Liberia Eye Centre, Monrovia, Liberia from July 2017 was developed. It can be accessed at the following link-https://www.lvpei.org/ aeye/lec.htm.

The limitations of this study are as follows. Firstly, the retrospective nature of the data set. Our study is a hospitalbased study which included only the patients who presented for an eye examination. Due to this nature, it must be emphasized that this study is not representative of the entire Liberian population. Nevertheless, it provides insight for the first time into the burden of ocular diseases in this given population.

In conclusion, refractive error was found to be the most common ocular diagnosis and the second most common presentation was cornea and anterior segment disorders in Liberia. In children aged 16 years and under, cornea and anterior segment related disorders were the most common ocular diagnosis. The description of various ocular diseases and their clinical presentation for the first time in a Liberian population provides the opportunity for further research. The digitization of eye care using electronic medical record systems and availability of real time analytics is a progressive step forward to help formulate health policy to combat avoidable blindness across Liberia.

\section{ACKNOWLEDGEMENTS}

The authors would like to acknowledge the untiring efforts of their colleagues Late. Sam Balasundaram and Rajshekar who enabled the establishment of the Liberia Eye Center in Monrovia. The authors also thank the eye Smart EMR\& AEye team at the L V Prasad Eye Institute, specially Vadapalli Ranganath, Mohammed Pasha and Yasaswi Leela Ram for their support in providing the data. This paper is dedicated to the memory of our dear colleague Late. Sam Balasundaram.

\section{FUNDING SOURCES}

None.

\section{COMPETING INTERESTS}

The authors completed the Unified Competing Interest form at http://www.icmje.org/coi_disclosure.pdf (available upon request from the corresponding author), and declare no conflicts of interest.

\section{CORRESPONDENCE TO:}

Dr. Gurcharan Singh

Department of Comprehensive Ophthalmology

Liberia Eye Center

Monrovia

Liberia

gs.kalra@yahoo.com 


\section{REFERENCES}

1. Liberia Institute of Statistics and Geo-Information Services. 2008 National Population and Housing Census Final Results: Population by County. Population and Housing Census 2017, Republic of Liberia.

2. Neumann E, Gunders AE. Ocular lesions of Onchocerciasis in Liberia. Am J Ophthalmol. 1963;56(4):573-588. doi:10.1016/0002-9394(63)9000 7-2

3. Michaelson IC. Ophthalmology in developing countries. Am J Ophthalmol. 1965;59(3):409-412. do i:10.1016/0002-9394(65)93737-2

4. Frucht-Pery J, Feldman ST. Cataract surgery in a leprosy population in Liberia. Int J Lepr Other Mycobact Dis. 1993;61:20-24.

5. Browning DJ. West African crystalline maculopathy. Ophthalmology. 2004;111(5):921-925. $\underline{\mathrm{d}}$ oi:10.1016/j.ophtha.2003.09.030

6. Jennings A, Bilous M, Asimakis P, Maloof AJ. Mycobacterium tuberculosis presenting as chronic red eye. Cornea. 2006;25(9):1118-1120. doi:10.1097/0 1.ico.0000240097.99536.82
7. Ministry of Health and Social Welfare. Republic of Liberia. Rapid Assessment of Avoidable Blindness Liberia; 2012.

8. Shantha JG, Crozier I, Hayek BR, et al. Ophthalmic manifestations and causes of vision impairment in Ebola Virus Disease survivors in Monrovia, Liberia. Ophthalmology. 2017;124(2):170-177. doi:10.1016/j.op htha.2016.10.011

9. Douglas G, Altman ME, Gotzsche PC. The STROBE Statement (Strengthening the report of observational studies in epidemology. University of Bern, Institute of Social and Preventive Medicine, Clinical Epidemiology \& Biostatistics.

10. Das AV, Rath S, Naik MN, Ali MJ. The incidence of lacrimal drainage disorders across a tertiary eye care network: Customization of an indigenously developed Electronic Medical Record System-eyeSmart. Ophthal Plast Reconstr Surg. 2019;35(4):354-356. doi:10.1097/i op.0000000000001257 